\title{
Steroid for epidural injection in spinal stenosis: a systematic review and meta-analysis
}

This article was published in the following Dove Press journal:

Drug Design, Development and Therapy

30 January 2015

Number of times this article has been viewed

\author{
Kuan Liu* \\ Pengcheng Liu* \\ Run Liu \\ Xing Wu \\ Ming Cai
}

Department of Orthopaedics, Shanghai Tenth People's Hospital, Tongji University School of Medicine, Shanghai, People's Republic of China

*These authors contributed equally to this work
Correspondence: Xing Wu; Ming Cai No 30 I Middle Yanchang Road, Shanghai Tenth People's Hospital, Shanghai, 200072, People's Republic of China Email orthopedics_dsyy@126.com; cmdoctor@tongji.edu.cn
Purpose: To investigate the effectiveness and safety of epidural steroid injections in patients with lumbar spinal stenosis (LSS).

Methods: We performed a search on the CENTRAL, Pubmed, Embase and Cochrane databases up to September 2014. We recovered 17 original articles, of which only 10 were in full compliance with the randomized controlled trial (RCT) criteria. These articles were reviewed in an independent and blinded way by two reviewers who were previously trained to extract data and score their quality by the criteria of the Cochrane Handbook (5.1.0).

Results: We accepted ten studies with 1,010 participants. There is minimal evidence that shows that epidural steroid injections are better than lidocaine alone, regardless of the mode of epidural injection. There is a fair short-term and long-term benefit for treating spinal stenosis with local anesthetic and steroids.

Conclusions: This meta-analysis suggests that epidural steroid injections provide limited improvement in short-term and long-term benefits in LSS patients.

Keywords: lumbar spinal stenosis, epidural injection, steroid, local anesthetic, chronic pain

\section{Introduction}

Lumbar spinal stenosis (LSS) is a degenerative disease that affects the lumbar spine. LSS can cause back and leg pain due to the compression of neuronal structures and intraspinal vasculature due to the narrowing of the spinal canal. LSS is quite common in people older than 65 years, and its most significant clinical symptom is intermittent neurogenic claudication. Neurogenic claudication is characterized by pain, paresthesia, and cramping in one or both legs. ${ }^{1}$ It is caused suddenly by walking and prolonged standing and can be relieved through sitting and bending forward.,3

Neurogenic claudication is a main reason leading to disability and lost independence in the elderly population. ${ }^{4}$ The patients with symptomatic LSS not only suffer from back and leg pain, but are also at high risk for developing serious complications. Disability and lost independence may lead to physical deterioration and obesity, which may eventually lead to serious health problems. ${ }^{5}$ Those afflicted have more serious walking limitations than individuals with knee or hip osteoarthritis. ${ }^{6}$ Consequently, their restricted ability to walk and stand lead to a significant decrease in quality of life. ${ }^{7-9}$

The rate of surgery for LSS has risen dramatically, especially in the USA. ${ }^{10,11}$ Some good outcomes from surgery have been demonstrated, but the literature has also suggested limited long-term benefits when compared to nonsurgical management. ${ }^{12,13}$ Some conservative treatment is recommended prior to surgical intervention. Researchers have focused on the use of epidural steroid injections to treat pain due to $\mathrm{LSS}^{14-23}$ 
Because pain and limited walking are the main impaired functions in patients with LSS, decreasing pain and improving walking ability are the primary goals for treatment. ${ }^{3}$ Two systematic reviews on epidural steroid injections for LSS are available. ${ }^{24,25}$ However, whether epidural steroid injections can relieve pain and improve walking ability in patients with LSS in short-term and long-term follow-ups is unclear. It is important to evaluate the role of epidural steroid injection treatments to manage patients with LSS. Therefore, we undertook a systematic review and meta-analysis of all the published literature to evaluate the effectiveness and safety of epidural steroid injection interventions for the treatment of LSS.

\section{Materials and methods}

We conducted this systematic review and meta-analysis according to the guidelines of the Cochrane Handbook for Systematic Reviews of Interventions (Version 5.1.0; Oxford, UK). ${ }^{26}$

\section{Search strategy}

The Cochrane library, Google Scholar, CENTRAL, Pubmed and Embase databases were searched independently by two investigators (KL and PCL), and relevant studies published before September 2014 were retrieved. The search strategy was based on a combination of the following medical subject headings (MeSH) and keywords: "steroid", "spinal stenosis", "pain", "epidural injection", and "local anesthetic". No restriction to specific languages or years of publication were included. The "related articles" function was used to broaden the search. The reference lists of the selected studies were also examined manually to identify relevant studies that were not discovered during the database searches. The corresponding authors were contacted when additional information was needed.

\section{Study selection}

We included randomized controlled trials (RCTs) that evaluated the efficacy and safety of epidural injections of steroids plus local anesthetic versus local anesthetic alone for the treatment of LSS patients. The inclusion criteria for the systematic review and meta-analysis were as follows: (1) randomized controlled trials in adults with LSS with epidural injection treatment; (2) clinical or radiological diagnosis of LSS; (3) describe neurogenic claudication with back (leg) pain and gait assessment; (4) provide the dosage and route of epidural steroid injection administration; and (5) outcomes measured, such as walking ability, pain intensity, quality of life, and global improvement. Studies evaluating radiculopathy caused by disc lesions were excluded. Studies with mixed populations were only included if the data for neurogenic claudication due to lumbar spinal stenosis were provided.

\section{Outcome measures}

All of the eligible studies were reviewed for baseline data (such as age and sex), intervention (such as epidural injection administration method, dose and duration) and outcome measures. Both subjective and objective functional outcome measurements were used to evaluate the data. However, the primary key polled outcomes were the pain scale (such as visual analog scale [VAS]) and walking ability. Adverse effects of epidural steroid injections were also examined. The quality of eligible studies was also assessed according to the Cochrane Handbook for Systematic Reviews of Interventions 5.1.0.

\section{Quality assessment}

The titles and abstracts of the publications were reviewed using the previously mentioned selection criteria by two readers (KL and PCL). The data extraction of all of the variables and outcomes of interest and assessment of the methodological quality were performed independently by two investigators. Any disagreement was resolved by discussion and consensus. The methodological quality of the trials was assessed using the Cochrane Handbook for Systematic Reviews of Interventions 5.1.0.

\section{Statistical methods}

Statistical analysis was performed by Review Manager 5.3.3 (Cochrane Collaboration, Nordic Cochrane Centre, Copenhagen, Denmark). For dichotomous variables, the relative risks (RRs) were measured with 95\% confidence intervals (CIs), while the weighted mean difference (WMD) was measured with the $95 \%$ CIs for continuous variables. $P$-values $<0.05$ were considered statistically significant, and the $95 \%$ CIs are reported. Statistical heterogeneity among studies was evaluated by Q-statistic and quantified by the $I^{2}$ statistic. Both a fixed-effects model and a random-effects model were used to obtain summary RRs or WMDs. If the Q or $I^{2}$ statistic was significant, a random-effects model was used. Otherwise, a fixed-effects model was used. Funnel plots and the Egger test (with $P<0.05$ considered statistically significant) were created to visually evaluate the presence of publication bias. A sensitivity analysis was also conducted, in which the RCTs were excluded to determine the stability of the combined RRs or WMDs. 


\section{Results}

\section{Literature search}

The initial literature search retrieved 101 relevant articles, and duplicates were discarded. After a careful screen of the titles, 84 articles were excluded as they did not cover the topic of interest. After reviewing the abstracts, seven more articles were excluded (one editorial and six reviews), leaving ten studies for further full publication review. Therefore, ten studies matched the selection criteria and were suitable for meta-analysis,,${ }^{1423}$ and all of them were prospective randomized control trials (Figure 1). A total of 1,010 patients (498 who received epidural steroid injection and 512 who received epidural local anesthetic injection) were enrolled in the studies. The key characteristics of the included studies are summarized in Table 1. All the studies involved patients with LSS and a follow-up of at least 6 weeks. Ten level I-II studies from 1985 to 2014 that compared epidural steroid injection with epidural local anesthetic injection for the treatment of
LSS prospectively and randomly were identified. On review of the data extraction, there was $100 \%$ agreement between the two investigators.

Figure 2 summarizes the methodological quality of the studies. All of the studies were RCTs with a high level of methodological quality. Thus, the methodological bias of this study was low.

\section{Main analysis}

Table 2 summarizes the outcomes of this meta-analysis. Minimal or no significant difference was found between the epidural steroid injection group and the epidural local anesthetic injection group for the short-term benefit, specifically, changes in the Roland-Morris Disability Questionnaire (RMDQ) Score (WMD, -1.80 , 95\% $\mathrm{CI},-2.82$ to $-0.78 ; P=0.0005)$ for 3 weeks, changes in the leg pain VAS score (WMD, $-7.00,95 \% \mathrm{CI},-12.73$ to $-1.27 ; P=0.02$ ) for 3 weeks, changes in the back pain

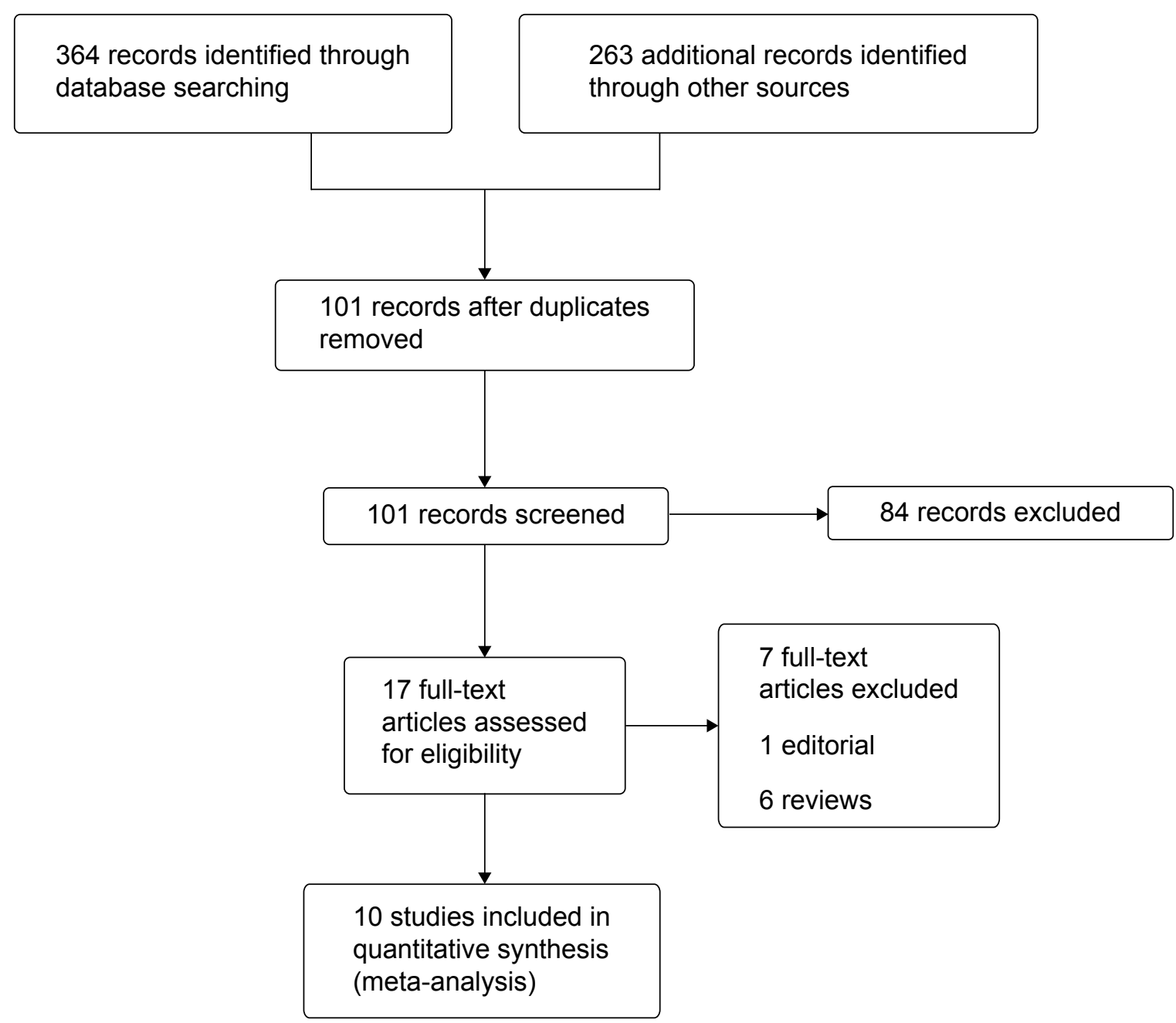

Figure I Flow diagram of the study identification. 


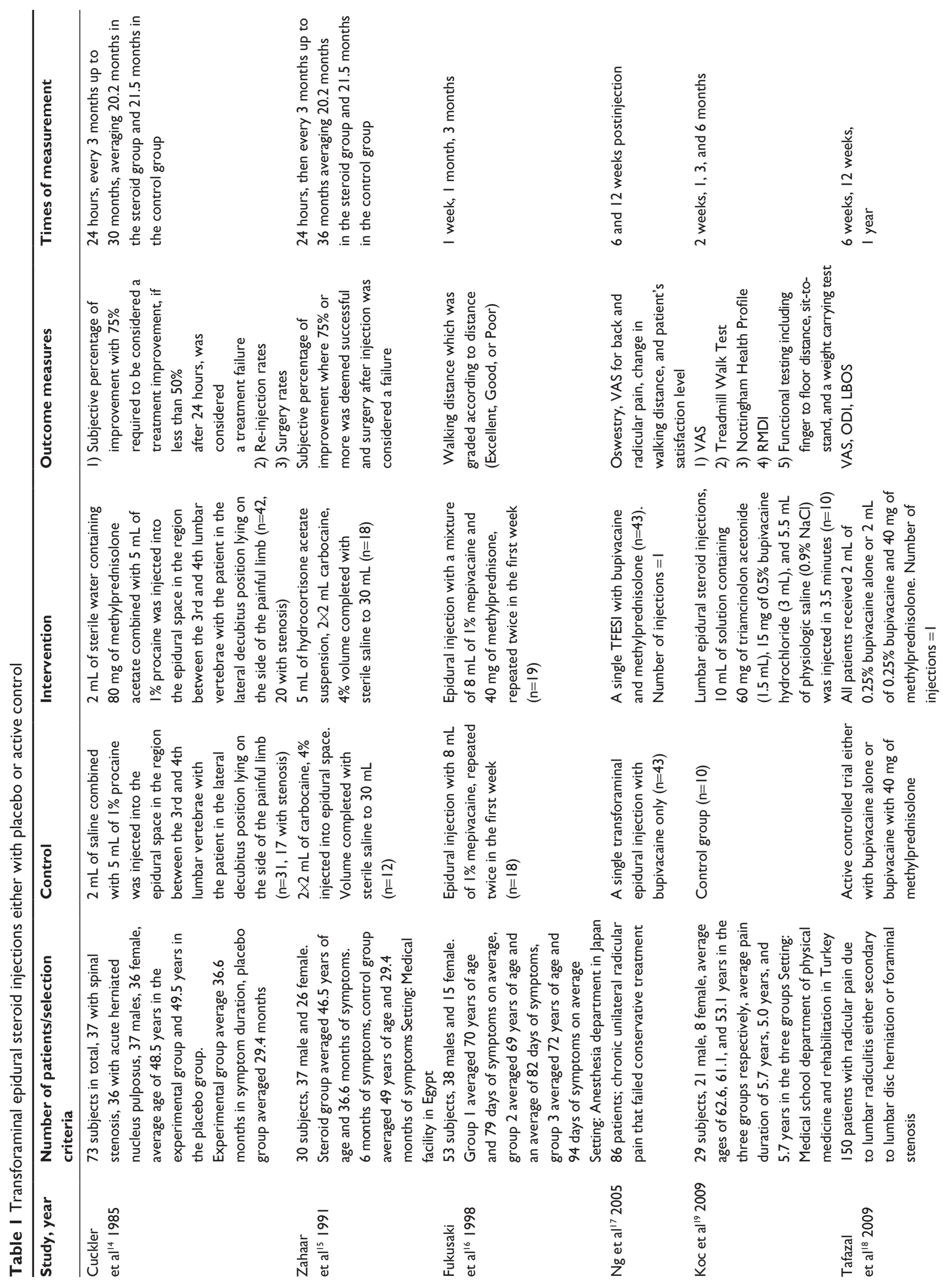




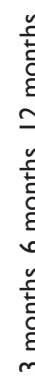
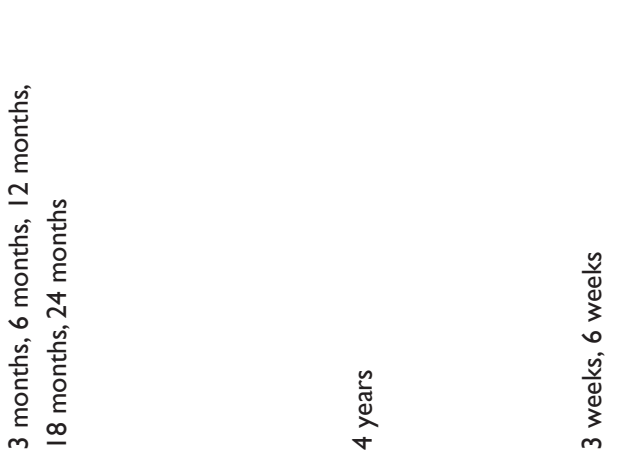

|
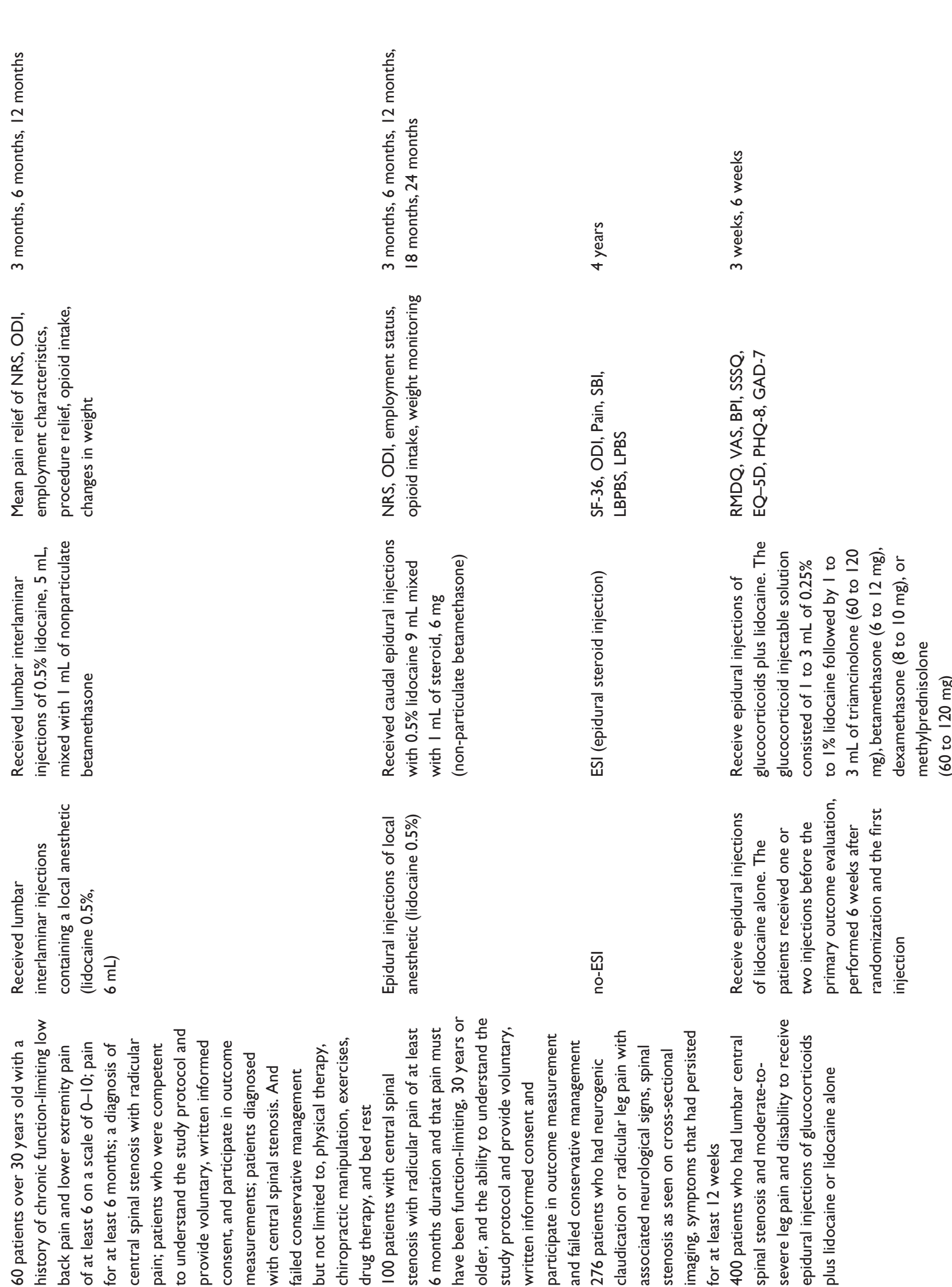

$\sqrt{1020}$
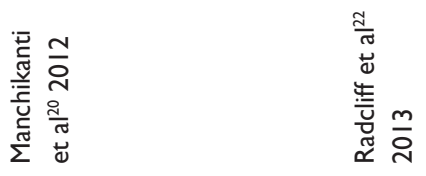

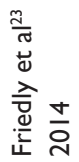

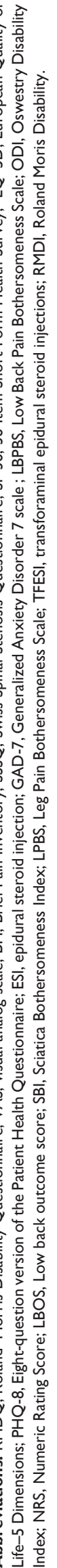




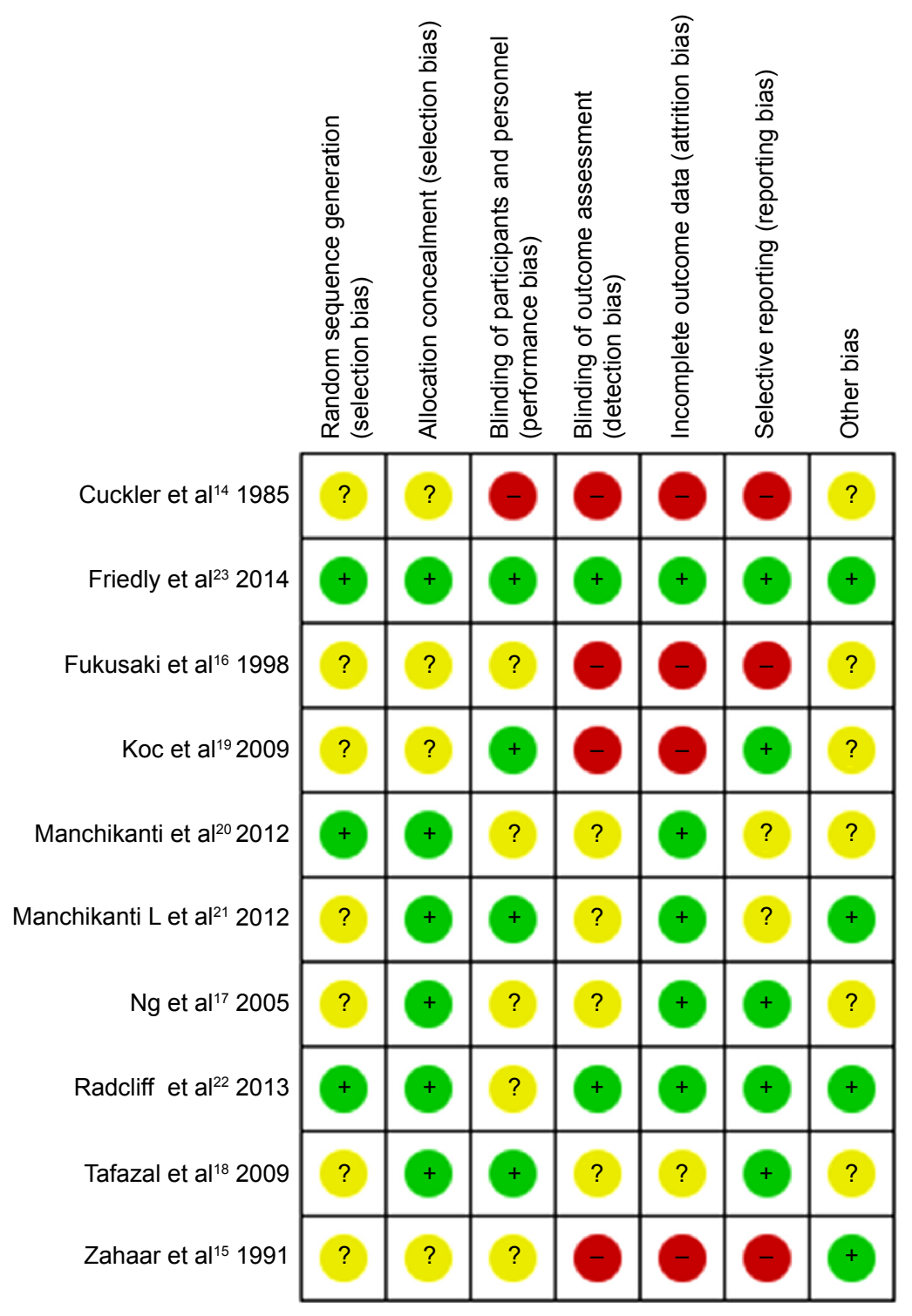

Figure 2 Risk of bias summary: a review of authors' judgments about each risk of bias item for each included study.

VAS score (WMD, 0.60, 95\% CI, 0.07 to $1.13 ; P=0.03$ ) for 3 weeks, Swiss Spinal Stenosis Questionnaire (SSSQ) subscales for symptoms (WMD, $-0.20,95 \% \mathrm{CI},-0.34$ to $-0.06 ; P=0.05$ ) for 3 weeks, and European Quality of Life-5 Dimensions (EQ-5D) (WMD, 0.04, 95\% CI, 0.00 to $0.08 ; P=0.03$ ) for 3 weeks. Because no significant heterogeneity was observed for the above comparisons, the fixed-effects model was subsequently used, as no significant clinical heterogeneity was found between the studies.

In terms of long-term benefit, there was significant difference between the epidural steroid injection group and the epidural local anesthetic injection group in terms of changes in bodily pain (BP) and physical function (PF) subscale scores, specifically, changes in the BP subscale scores (WMD, $-11.90,95 \% \mathrm{CI},-22.72$ to $-1.08 ; P=0.03$ ) for 3 years and (WMD, $-12.90,95 \% \mathrm{CI},-23.88$ to $-1.92 ; P=0.02)$ for 4 years and changes in the PF subscale scores (WMD, -14.30 , 95\% CI, -25.28 to $-3.32 ; P=0.01$ ) for 4 years. Because no significant heterogeneity was observed for the change from the BP and PF subscale scores, the fixed-effects model was subsequently used, as no significant clinical heterogeneity was found between the studies.

With respect to the epidural local anesthetic injection group, there was no significant difference for most outcome measures, such as the Brief Pain Inventory (BPI) Interference Scale (3 weeks, 6 weeks); SSSQ Physical-Function Subscales (3 weeks, 6 weeks); Eight-question version of the Patient Health Questionnaire (PHQ-8) (3 weeks, 6 weeks); Generalized Anxiety Disorder 7 (GAD-7) scale (3 weeks, 6 weeks); Oswestry Disability Index (ODI) score (6 weeks, 3 months, 


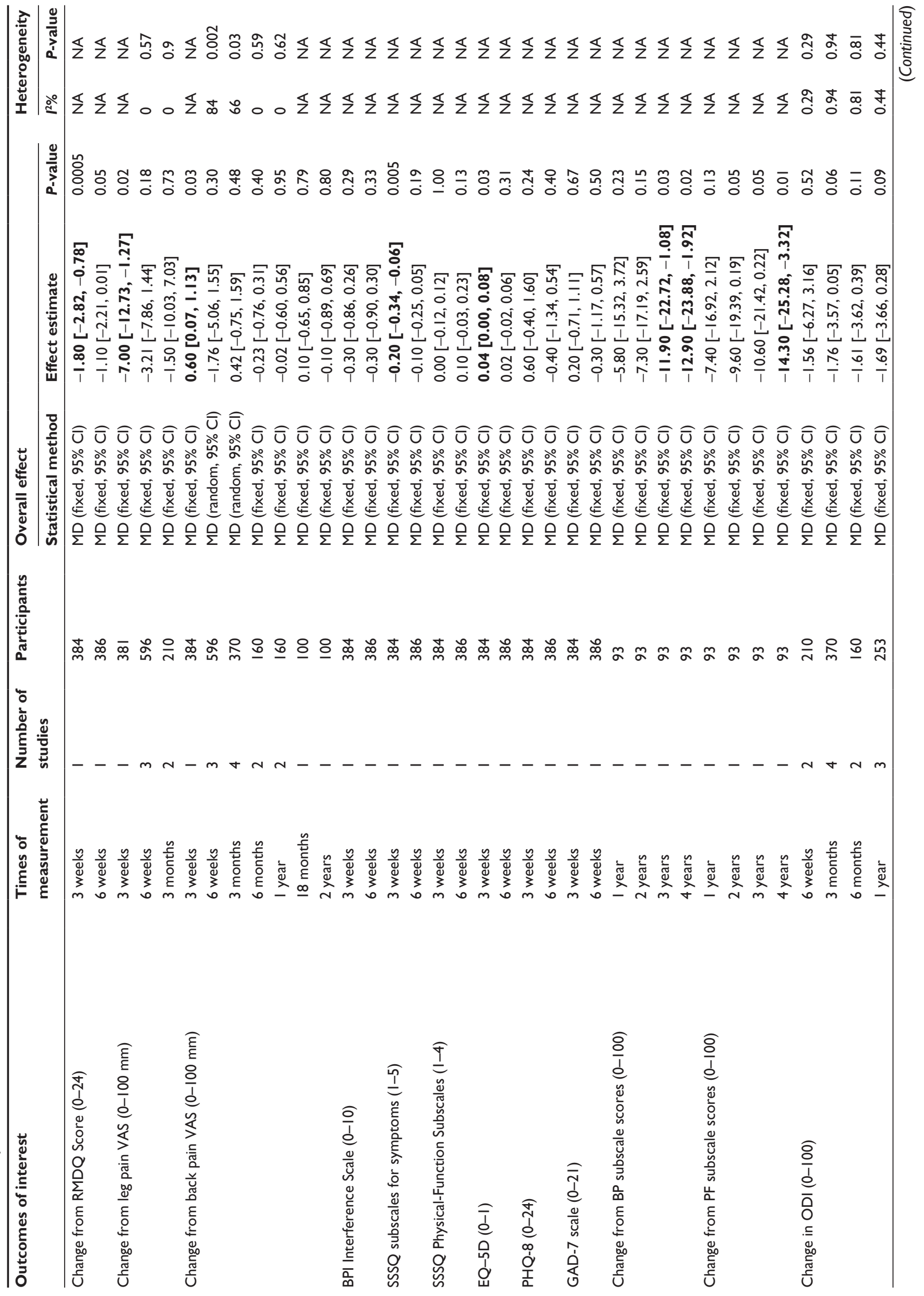




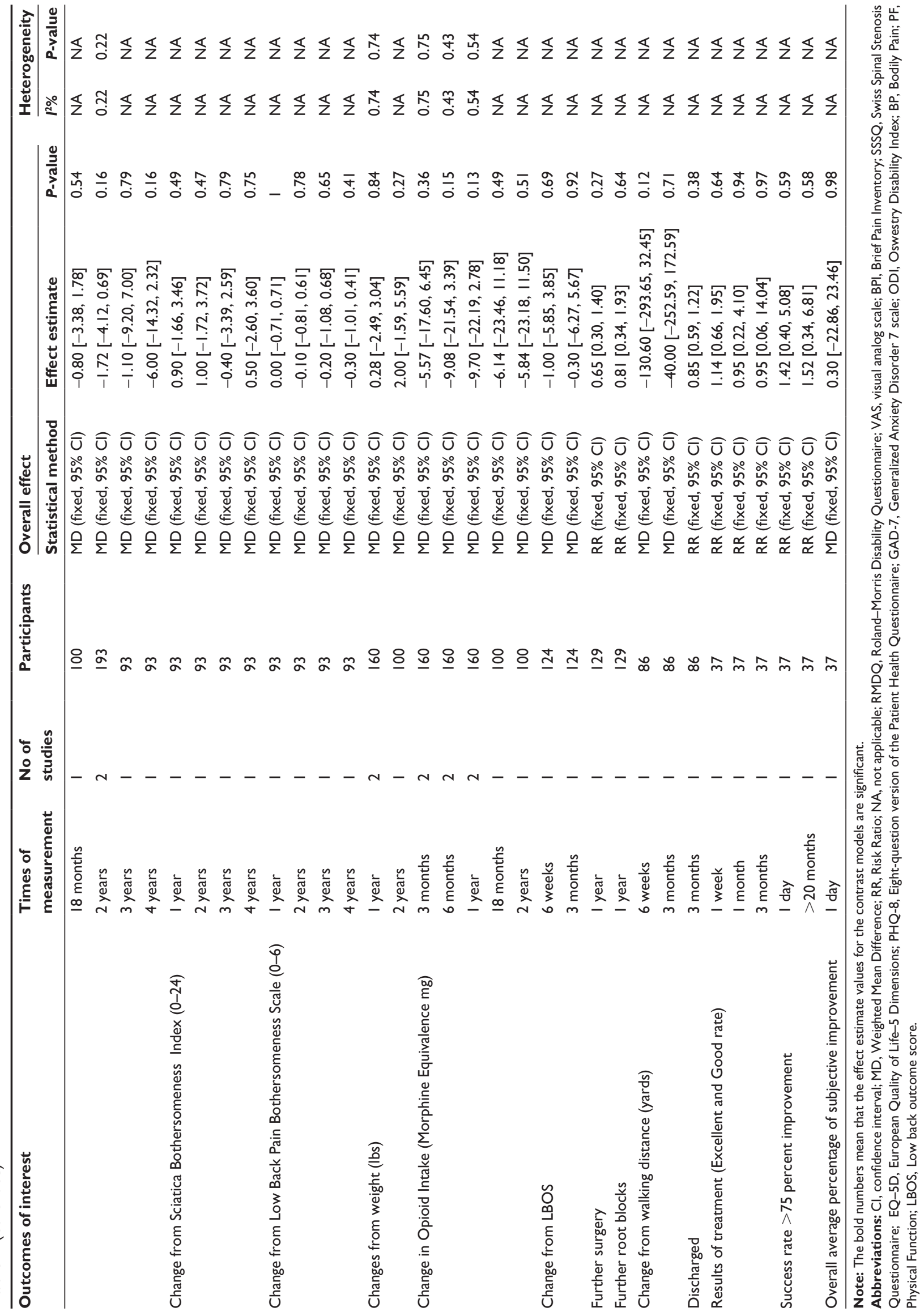


6 months, 1 year, 18 months, 2 years, 3 years, 4 years); Sciatica Bothersomeness Index (1 year, 2 years, 3 years, 4 years); Low Back Pain Bothersomeness Scale (1 year, 2 years, 3 years, 4 years); weight change (lbs) (1 year, 2 years); Opioid Intake changes (Morphine Equivalence mg) (3 months, 6 months, 1 year, 18 months, 2 years); low back outcome score (LBOS) (6 weeks, 3 months); further surgery rate (1 year); further root blocks rate (1 year); walking distance changes (yards) (6 weeks, 3 months); discharged rate (3 months); treatment results (Excellent and Good rate) (1 week, 1 month, 3 months); success rate ( $>75$ percent improvement) ( 1 week, 1 month, 3 months); and overall average percentage of subjective improvement (1day). Because no significant heterogeneity was observed for the change from the BP and PF subscale scores, the fixed-effects model was subsequently used, as no significant clinical heterogeneity was found between the studies.

\section{Publication bias}

We did not draw funnel plots because the trials for each comparison were less than ten.

\section{Discussion}

LSS is a significant problem that affects many elderly adults annually. Walking limitation due to neurogenic claudication of LSS is thought to be the hallmark of disability. ${ }^{27}$ Walking ability is essential for most daily living activities and has been identified as a relatively important outcome in LSS. 28,29 Despite the rising prevalence of LSS, only a few studies have investigated nonsurgical treatment modalities. This systematic review and meta-analysis of RCTs summarizes all of the available studies on the use of epidural steroid injection for LSS patients. We were only able to identify ten randomized, double-blind, controlled trials involving a total of 1,010 patients. Overall, the evidence described that epidural steroid injections offered minimal or no effective analgesic and do not significantly improve walking ability in LSS patients, regardless of the method of epidural injection.

Overall, epidural steroid injection treatment seems to be quite safe. While there were very few adverse effects reported in these RCTs, the safety of epidural steroid injections needs to be further evaluated. Due to the lack of significant adverse effects, epidural steroid injections are thought to be a safe treatment for future clinical research.

Now it was hard to address through meta-analysis due to the heterogeneity and diversity of the criteria in patient selection, different epidural injection approaches, doses, follow-up lengths, and differences in sample sizes. Another weakness was the different outcome measurements, such as pain and walking ability assessments, which were measured in different ways.

In 2013, North America Spine Society's (NASS) Evidence-Based Clinical Guideline Development Committee developed an evidence-based clinical guideline ${ }^{30}$ for the diagnosis and treatment of degenerative LSS. They found evidence supporting the recommendation of epidural steroid injection therapy, elaborating a $\mathrm{B}$ recommendation in favor of it use. However, this systematic review was based on only four ${ }^{14,16,19,31}$ trials.

The limitations of this meta-analysis were as follows. First, the epidural injection approaches, doses, frequencies, and duration in each trial were not exactly the same, which may have influenced the outcomes of interest. Second, some parameters of interest demonstrated a large degree of heterogeneity. The heterogeneity of change from back pain VAS score may be the result of bias from the different assessment methods used in the various trials. Last but not least, meta-analyses require greater patient numbers, and insufficient patients were included in this study. As such, larger high level studies are required to show the superiority of epidural steroid injection therapy for treating neurogenic claudication due to LSS.

\section{Conclusion}

On the basis of the reviewed trials, when compared with local anesthetic, we found no evidence that epidural steroid injection therapy provides a statistically significant improvement in pain symptoms or walking ability in LSS patients. Moreover, local anesthetic appears to play an unusual role in its efficacy for pain control. Additional better and rigorous studies with long-term observation are required to elucidate the effectiveness of epidural steroid injection treatment for LSS.

\section{Acknowledgments}

We would like to thank Run Liu for his assistance in developing the search strategy and retrieving relevant articles.

\section{Disclosure}

The authors report no conflicts of interest in this work.

\section{References}

1. Yaksi A, Ozgonenel L, Ozgonenel B. The efficiency of gabapentin therapy in patients with lumbar spinal stenosis. Spine (Phila Pa 1976). 2007;32(9):939-942.

2. Suri P, Rainville J, Kalichman L, Katz JN. Does this older adult with lower extremity pain have the clinical syndrome of lumbar spinal stenosis? JAMA. 2010;304(23):2628-2636.

3. Katz JN, Harris MB. Clinical practice. Lumbar spinal stenosis. $N$ Engl J Med. 2008;358(8):818-825. 
4. Fanuele JC, Birkmeyer NJ, Abdu WA, Tosteson TD, Weinstein JN. The impact of spinal problems on the health status of patients: Have we underestimated the effect? Spine (Phila Pa 1976). 2000;25(12): 1509-1514.

5. Johnsson KE, Rosen I, Uden A. The natural course of lumbar spinal stenosis. Acta Orthop Scand Suppl. 1993;251:67-68.

6. Winter $\mathrm{CC}$, Brandes $\mathrm{M}$, Muller $\mathrm{C}$, et al. Walking ability during daily life in patients with osteoarthritis of the knee or the hip and lumbar spinal stenosis: A cross sectional study. BMC Musculoskelet Disord. 2010;11:233.

7. Iversen MD, Katz JN. Examination findings and self-reported walking capacity in patients with lumbar spinal stenosis. Phys Ther. 2001;81(7): 1296-1306.

8. Jonsson B, Annertz M, Sjoberg C, Stromqvist B. A prospective and consecutive study of surgically treated lumbar spinal stenosis. Part I: Clinical features related to radiographic findings. Spine (Phila Pa 1976). 1997;22(24):2932-2937.

9. Jansson KA, Nemeth G, Granath F, Jonsson B, Blomqvist P. Health-related quality of life (EQ-5D) before and one year after surgery for lumbar spinal stenosis. J Bone Joint Surg Br. 2009;91(2): $210-216$.

10. Taylor VM, Deyo RA, Cherkin DC, Kreuter W. Low back pain hospitalization. Recent United States trends and regional variations. Spine (Phila Pa 1976). 1994;19(11):1207-1212, 1213.

11. Rajaee SS, Bae HW, Kanim LE, Delamarter RB. Spinal fusion in the United States: Analysis of trends from 1998 to 2008. Spine (Phila Pa 1976). 2012;37(1):67-76.

12. Atlas SJ, Keller RB, Wu YA, Deyo RA, Singer DE. Long-term outcomes of surgical and nonsurgical management of lumbar spinal stenosis: 8 to 10 year results from the maine lumbar spine study. Spine (Phila Pa 1976). 2005;30(8):936-943.

13. Atlas SJ, Keller RB, Wu YA, Deyo RA, Singer DE. Long-term outcomes of surgical and nonsurgical management of sciatica secondary to a lumbar disc herniation: 10 year results from the maine lumbar spine study. Spine (Phila Pa 1976). 2005;30(8):927-935.

14. Cuckler JM, Bernini PA, Wiesel SW, et al. The use of epidural steroids in the treatment of lumbar radicular pain. A prospective, randomized, double-blind study. J Bone Joint Surg Am. 1985;67(1):63-66.

15. EL ZAHAAR MS. The value of caudal epidural steroids in the treatment of lumbar neural compression syndromes. J Neurol Orthop Med Surg. 1991;12:181-184.

16. Fukusaki M, Kobayashi I, Hara T, Sumikawa K. Symptoms of spinal stenosis do not improve after epidural steroid injection. Clin J Pain. 1998;14(2):148-151.

17. $\mathrm{Ng} \mathrm{L}$, Chaudhary N, Sell P. The efficacy of corticosteroids in periradicular infiltration for chronic radicular pain: A randomized, double-blind, controlled trial. Spine (Phila Pa 1976). 2005;30(8):857-862.
18. Tafazal S, Ng L, Chaudhary N, Sell P. Corticosteroids in peri-radicular infiltration for radicular pain: A randomised double blind controlled trial. One year results and subgroup analysis. Eur Spine J. 2009; 18(8):1220-1225

19. Koc Z, Ozcakir S, Sivrioglu K, Gurbet A, Kucukoglu S. Effectiveness of physical therapy and epidural steroid injections in lumbar spinal stenosis. Spine (Phila Pa 1976). 2009;34(10):985-989.

20. Manchikanti L, Cash KA, McManus CD, Pampati V, Fellows B. Results of 2-year follow-up of a randomized, double-blind, controlled trial of fluoroscopic caudal epidural injections in central spinal stenosis. Pain Physician. 2012;15(5):371-384.

21. Manchikanti L, Cash KA, McManus CD, et al. Lumbar interlaminar epidural injections in central spinal stenosis: Preliminary results of a randomized, double-blind, active control trial. Pain Physician. 2012;15(1): 51-63.

22. Radcliff K, Kepler C, Hilibrand A, et al. Epidural steroid injections are associated with less improvement in patients with lumbar spinal stenosis: A subgroup analysis of the Spine Patient Outcomes Research Trial. Spine (Phila Pa 1976). 2013;38(4):279-291.

23. Friedly JL, Comstock BA, Turner JA, et al. A randomized trial of epidural glucocorticoid injections for spinal stenosis. $N$ Engl J Med. 2014;371(1):11-21.

24. Parr AT, Manchikanti L, Hameed H, et al. Caudal epidural injections in the management of chronic low back pain: A systematic appraisal of the literature. Pain Physician. 2012;15(3):E159-E198.

25. Manchikanti L, Buenaventura RM, Manchikanti KN, et al. Effectiveness of therapeutic lumbar transforaminal epidural steroid injections in managing lumbar spinal pain. Pain Physician. 2012;15(3):E199-E245.

26. Moher D, Cook DJ, Jadad AR, et al. Assessing the quality of reports of randomised trials: Implications for the conduct of meta-analyses. Health Technol Assess. 1999;3(12):1-98.

27. Conway J, Tomkins CC, Haig AJ. Walking assessment in people with lumbar spinal stenosis: Capacity, performance, and self-report measures. Spine J. 2011;11(9):816-823.

28. Deen HJ, Zimmerman RS, Lyons MK, et al. Test-retest reproducibility of the exercise treadmill examination in lumbar spinal stenosis. Mayo Clin Proc. 2000;75(10):1002-1007.

29. Yamashita K, Hayashi J, Ohzono K, Hiroshima K. Correlation of patient satisfaction with symptom severity and walking ability after surgical treatment for degenerative lumbar spinal stenosis. Spine (Phila $\mathrm{Pa}$ 1976). 2003;28(21):2477-2481

30. Kreiner DS, Shaffer WO, Baisden JL, et al. An evidence-based clinical guideline for the diagnosis and treatment of degenerative lumbar spinal stenosis (update). Spine J. 2013;13(7):734-743.

31. Papagelopoulos PJ, Petrou HG, Triantafyllidis PG, et al. Treatment of lumbosacral radicular pain with epidural steroid injections. Orthopedics. 2001;24(2):145-149.
Drug Design, Development and Therapy

\section{Publish your work in this journal}

Drug Design, Development and Therapy is an international, peerreviewed open-access journal that spans the spectrum of drug design and development through to clinical applications. Clinical outcomes, patient safety, and programs for the development and effective, safe, and sustained use of medicines are a feature of the journal, which

\section{Dovepress}

has also been accepted for indexing on PubMed Central. The manuscript management system is completely online and includes a very quick and fair peer-review system, which is all easy to use. Visit http://www.dovepress.com/testimonials.php to read real quotes from published authors. 